\title{
Research on Teaching Chinese as a Foreign Language from the Perspective of Construction Grammar
}

\author{
Ying Huang1, Shuangyue Shao \\ ${ }^{1}$ Baoding University, Baoding, China \\ ${ }^{2}$ NO. 1 Hospital, Baoding, China \\ Email: hyingmm@126.com, Yue258@163.com
}

How to cite this paper: Huang, Y., \& Shao, S. Y. (2019). Research on Teaching Chinese as a Foreign Language from the Perspective of Construction Grammar. Creative Education, 10, 980-985.

https://doi.org/10.4236/ce.2019.105074

Received: April 26, 2019

Accepted: May 27, 2019

Published: May 30, 2019

Copyright () 2019 by author(s) and Scientific Research Publishing Inc. This work is licensed under the Creative Commons Attribution International License (CC BY 4.0).

http://creativecommons.org/licenses/by/4.0/

\begin{abstract}
According to construction grammar, grammatical description of all strata is to involve pairings of form and meaning, and the construction grammar can be applied to the teaching of Chinese as a foreign language. The author believes that the constructive interpretation of teaching Chinese as a foreign language should have a holistic constructional view; from simple construction to complex construction, from typical construction to atypical construction, we should also pay attention to the communicative function of discourse.
\end{abstract}

\section{Keywords}

Mode of Chinese Teaching Grammar, Chinese Teaching, Teaching Concept, Teaching Method

\section{Introduction}

With the rise of cognitive linguistics in the 1980s, Construction Grammar, as an important branch of cognitive linguistics, has gradually flourished. In addition, construction grammar theory has developed in response to generative grammar and other grammatical theories since the 1960s.

\section{A Summary of Construction Grammar}

The thinking of construction grammar originated from Fillmore, Kay, and O'Connor's (1988) case grammar at first, and then it has been extensively studied and popularized by Adele E. Goldberg (2007), which aroused extensive attention from international society. With people's understanding of semantic and pragmatic features, more and more attention has been paid to the study of spe- 
cific sentence patterns. However, many people tend to attribute the meaning of a sentence to individual lexical items. Specifically, although individual lexical items can provide a great deal of information, it is difficult to explain many linguistic problems in the research with a word-based or from top to bottom method. That is to say, verbs are not the only core of a sentence and specific semantic structures and their related formal expressions must be regarded as constructions independent of lexical items.

Construction grammar advocates the matching of form and meaning, and advocates that the construction is the center and the construction is regarded as the overall of which function is greater than the sum of the parts, rather than the simple sum of the meanings of the parts. Some linguistic phenomena prove that this kind of grammatical theory can't explain all the special linguistic phenomena. For example, the ditransitive form which we mentioned that the theory of valence analysis believes that verbs have power and one verb can dominate several act ants, so the verb is a valence verb. The verbs in the ditransitive form are usually trivalent verbs, but we find that in such sentences as "Chi Le Ta San Ge Ping Guo" and "Mai Le Da Niang San GeJi Dan", there are two actants behind the bivalent verbs, which seem to be incomprehensible with the valence theory, and the verbs in the ditransitive form should dominate two objects. However, in these two examples, whether it is the verb "Chi" or "Mai", we can say that we have eaten three apples, but we can't say that we ate him and we can say that we bought three eggs, but we can't say that we bought a lady. That is to say, in the ditransitive form, "Ta" and "Da Niang" are not dominated by the front verbs. In case of this, the academia began to use the theory of construction grammar to solve this problem which is not a verb or a function word that determines the meaning of a sentence, but a construction that determines the meaning of the whole sentence.

The rise of construction grammar provides a new perspective for language ontology research, language acquisition and teaching which is breaking the traditional grammatical concept of "verb-centered theory". Based on this theory, the thesis hopes to provide another teaching idea for our teaching of Chinese as a foreign language, constantly update and change the teaching methods and design, and solve some marginal language phenomena in teaching Chinese as a foreign language.

\section{Construction Application in Teaching Chinese as a Foreign Language}

In teaching Chinese as a foreign language, great attention has been paid to the teaching and research of sentence patterns. For example, the sentence pattern research group of Beijing Languages Institute has made a monographic study on the basic and key sentence patterns of modern Chinese, which has produced a series of results published in various issues of Chinese Teaching in the World (1989-1991). There are a lot of same happens in other sentence patterns and syn- 
taxes. However, we think that the traditional grammatical meaning of "sentence pattern and syntax" focuses on the structural form and characteristics of sentences. Although both of them have a closely relationship, it cannot be equated with "construction" which emphasizes two aspects of "construction" (structural formula) and "formation" (form-meaning pairs). With the continuous improvement and development of construction grammar theory, the proper use of construction grammar theory in teaching Chinese as a foreign language can enrich our teaching ideas.

\subsection{Holistic Constructional View}

Traditional grammatical concepts hold that verbs play a dominant role in sentences. Because there is no morphological change in Chinese, the grammatical meanings are expressed in word order and function words. Under the influence of the traditional grammatical concept of "verb-centered theory", Chinese teachers tend to pay more attention to verbs and function words in the teaching process which determine the meaning of the sentences. But as we mentioned earlier, if the instructor only focuses on the explanations of "Yao" and "Le", in the individual examples of "Ta Yao Qu Beijing" and "Xiao Ming Zuo Wan Zuo Ye Le", which is easier for the students to understand. However, when "Yao" and "Le" appear in the sentence at the same time, the students will find it difficult to understand, and even the sentence "Ta Yao Qu Beijing Le" is a wrong sentence, because the meaning of "Yao" and the grammatical meaning of "Le" are contradictory, which will cause students' misunderstanding.

The meaning of a sentence is not simply the sum of the meanings of phrases or words in a sentence. Construction grammar holds that construction is dominant in a sentence, and the meaning of a sentence is not simply the sum of parts of meaning. Therefore, we also mentioned earlier that if we regard a sentence like "Ta Yao Qu Beijing Le" as a construction like "S Yao V Le" which can be regarded as a whole, and the whole meaning of the construction is to do something immediately or soon. Only in this way, can the students not bite the words, understand the meaning of "Yao" and "Le", and then integrate them.

The enlightenment of constructional grammar is that some sentences should be interpreted as a whole structure rather than fragmented analysis.

\subsection{From Simple Construction to Complex Construction}

Chen Manhua (2009) cites such an example in his thesis "The Enlightenment of Constructive Grammar Theory to Second Language Teaching".

Example 1: what's the meaning of "There were many empty seats, so I found a window seat"?

1) There are many people in the snack bar.

2) There are not many people in the snack bar.

3) There are not enough seats in the snack bar.

4) There are no seats in the snack bar. 
This is a reading question. For native speakers of Chinese, this choice question is not difficult. But for learners who use Chinese as a foreign language, they will be in a dilemma of what is the meaning of "You De Shi"? According to the traditional grammatical concept, the teacher often tells the students "You" when having an explanation, which can be used as a verb, followed by a noun to indicate a kind of existence or belonging. For example, "She has an apple" and "There is a peach tree on the playground". But when the structure of "You De Shi" in Example 1 appears, the students don't know what it means. For "You", there are many kinds of structures, such as fixed phrases, phrases, idioms, sentences and so on.

Example 2: Yuan Zi Li You Yi KeShu.

Example 3: Ke Zhen You Ni De.

Example 4: You De Shi Qian.

Example 5: Du Shu Hen You Yong.

From the above four examples, we can see that four different constructions represent different constructional meanings. Example 2 is a general structure of the word "You", which means a kind of existential meaning, while the word "You" in Example 5 is also included in the Chinese dictionary. Both of the types are easier for students to grasp. But for Example 3 and 4, learners are not so easy to understand, so it requires teachers to start teaching from simple constructions in the process of teaching, in addition, it should be noted that learners should start from the overall constructional meaning when teaching these simple constructions, rather than one-way learners to explain "You", otherwise learners will learn the complex constructions of "Yao" in the future. When they do, they will fall into a misunderstanding.

\subsection{From Typical Construction to Atypical Construction}

From the perspective of constructional grammar, Chinese teaching should be from typical to atypical. On one side, typical has basic external form and core constructional meaning, while atypical derives from typical. Only by mastering typical constructions, can we better understand the atypical constructions derived from typical constructions. Taking the ditransitive construction as an example, the ditransitive construction is $\mathrm{V}+\mathrm{N} 1+\mathrm{N} 2$, which means "intentional giving transfer", which is the typical structure of the ditransitive. Learners can easily grasp the basic usage and construction meaning when learning such a typical ditransitive construction. However, when the following sentences appear, learners often have difficulty in understanding. For example:

Example 6: Di Gei Ta Yi Ge Kou Xin.

Example 7: Tou Le Qi Bai Shi San Fu Hua.

The ditransitive constructions in these two examples are atypical, which are derived from the typical ditransitive constructions, so it is difficult for learners to understand them. The enlightenment of constructional grammar is that in Chinese teaching, we can't generalize the ditransitive construction, but should dis- 
tinguish from the typical and atypical ditransitive, which is from the typical to the atypical and step by step. That is to say, atypical constructions are often derived from the basis of typical constructions, so learners can better grasp atypical constructions after learning the typical constructions.

\subsection{Emphasizing the Communicative Function of Discourse}

Construction is a pairing of form and function (meaning and discourse) that each pairing contains formal features and some communicative function. Among them, "discourse function" and "communicative function" include pragmatic function. In addition, the construction grammar theory holds that pragmatics and semantics are inseparable, which is breaking the traditional grammar view that they are separated.

Some linguistic facts show that the semantics of some linguistic components when they form sentences independently don't accord with our cognition. Teachers often regard such sentences as wrong sentences in their teaching, which is absolutely impossible to say. However, we find that when these single sentences are independent, there is no specific context and their meaning is contrary to cognition. In addition, they are valid in a certain context which requires the teachers to explain the sentences established in such a specific context in the process of teaching, rather than negating them wholly. In the process of teaching, teachers should attach importance to the communicative function of discourse, and give special explanations to some sentences established under specific circumstances, rather than affirming their absolute errors, so as to avoid causing misunderstanding among students.

\section{Conclusion}

Since 1980s, the rise of along-wind grammar has broken the traditional center of saying "verb" of grammar concept. It is to provide a new perspective for the analysis of Chinese grammar phenomenon. Many scholars use the theory of structure type of grammar to re-examine the double transitive, and way-structure type. It discusses the mode of grammatical significance of language acquisition and language phenomenon. This article is based on the mode of grammar theory. From a different perspective on Chinese teaching, we have new recognition on Chinese language teaching.

In addition, construction grammar doesn't negate the function of verbs and function words, but through some linguistic phenomena, we can see that the meaning of a sentence is not determined by a single verb, but by the whole construction, which requires teachers have a holistic constructional view; from simple construction to complex construction, from typical construction to atypical construction, we should also pay attention to the communicative function of discourse and the matching of form and meaning in the process of teaching, which provides a new way of thinking and method for teaching Chinese as a foreign language, so as to achieve better practice and application effect. 


\section{Funding}

Project: 2018 Hebei Provincial Social Science Fund Project. Project Name: A Study on the Subjective Quantitative Construction with Comparative Structure of Modern Chinese. Project No. HB18YY001.

\section{Conflicts of Interest}

The authors declare no conflicts of interest regarding the publication of this paper.

\section{References}

Chen, M. H. (2009). The Enlightenment of Constructive Grammar Theory to Second Language Teaching. Language Teaching and Research, No. 4, 64-70.

Fillmore, C. J., Kay, P., \& O’Connor, M. C. (1988). Regularity and Idiomaticity in Grammatical Constructions: The Case of Letalone. Language, 64, 501-538. https://doi.org/10.2307/414531

Goldberg, A. E. (2007). Construction: Study on the Construction Grammar of Argument Structure. Wu, H.B, Translated, Beijing: Peking University Press, 71-78. 